\title{
UTILIDAD DE LA HUELGA. APROXIMACIONN A UN ESTUDIO SOBRE SUS EXPECTATIVAS Y COSTOS
}

\author{
WILLIAM THAYER ARTEAGA* \\ Pontificia Universidad Católica de Chile
}

1. Hacia fines del siglo XIX y las primeras décadas de la nueva centuria, diversos factores concurrieron a agudizar sus dramáticas características: a) Las inaceptables condiciones de vida y trabajo de los obreros; b) El analfabetismo $-77 \%$ en 1875 y $60 \%$, en $1916^{1}$ - y una nula o mínima calificación profesional y productividad en ellos; c) La ausencia de normativas legales que regularan los conflictos y negociaciones; d) El desconocimiento por parte de los obreros de las posibilidades que tenía la empresa de atender a sus exigencias sin comprometer su estabilidad económica o viabilidad; e) El desconocimiento y desinterés del empleador por la situación y destino de sus obreros; f) La ausencia o debilidad de los factores que pudieren crear un sentido de comunidad de intereses entre la empresa y los trabajadores; g) La fácil sustitución de estos por su baja calificación y la simplicidad de los procesos industriales; h) La carencia de normas legales que pudieren regular los conflictos; i) El bajo nivel cultural de los protagonistas; y j) La creciente influencia de las tendencias socialistas marxistas, agudizadas por la carencia de un sentido social en el mundo empresarial y en la autoridad del Estado.

2. En las primeras décadas del siglo XX se precipitaron acontecimientos mundiales $\mathrm{y}$ nacionales que cambiaron el cuadro, pero estuvieron lejos de resolver la situación, comúnmente llamada "cuestión social". Entre ellos cabe mencionar: a) La Primera Guerra Mundial; b) La Revolución bolchevique; c) La aparición de la OIT; d) La candidatura y triunfo de Arturo Alessandri en 1920; e) El proyecto de Código del Trabajo de 1921, la revolución de septiembre de 1924 y la legislación laboral que derivó de ella (leyes $\mathrm{N}^{\circ} 4053$ a 4059). Para los efectos de este estudio, cabe destacar la ley $\mathrm{N}^{\circ}$ 4056, sobre Tribunales de Conciliación y Arbitraje, aprobada el 8 de septiembre de 1924 -junto a las demás de la serie-, y fue precedida por un decreto supremo $\mathrm{N}^{\circ} 4353$, de 1917 , el cual estableció la primera reglamentación de los conflictos laborales; g) El Código de 1931 -D.F.L. $\mathrm{N}^{\circ} 178$ de 13 de mayo de 1931-, promulgado bajo el primer gobierno de Ibánez, con el que se inició una larga historia de reformas, culminada en el D.F.L. $N^{\circ} 1$ de 1994, el D.F.L. $\mathrm{N}^{\circ} 1$ de 2003 que contiene el texto refundido, coordinado y sistematizado del Código del Trabajo y demás modificaciones posteriores.

3. El progreso complejo y paralelo de legislación social, educación pública y privada y desarrollo económico y político, permitió que avanzaran, con sobresaltos y retrocesos, por un camino en definitiva civilizado y pacífico, las relaciones colectivas de trabajo, pese al

\footnotetext{
* Abogado. Profesor Emérito de la Pontificia Universidad Católica de Chile.

${ }^{1}$ PONCE, Homero. Historia del Movimiento Asociativo Laboral Chileno. Tomo I. Santiago: Editorial Alba, 1986, p.86.
} 
William Thayer Arteaga / Utilidad de la buelga. Aproximación a un estudio sobre sus expectativas y costos

permanente asedio del marxismo-leninismo. La huelga se mantuvo como un elemento irracional, amenazante, pero no desbordado, que determinaba una solución final mediante un juego de quién aguanta más.

4. Las reformas del Plan Laboral -D.L. N²758 de 1979-, y posteriormente las leyes $\mathrm{N}^{\circ} 19.069$ de 1991 y $\mathrm{N}^{\circ} 19.759$, de 2001 , concordaron en una solución legal fundada en cierto contrapeso entre las aspiraciones de los huelguistas y las condiciones que aceptan los reemplazantes provisionales. Con todo, esa opción ha sido fuertemente combatida y el debate sigue vigente.

5. Largos años de actividad profesional, académica, funcionaria como asesor sindical, negociador colectivo, ministro del Trabajo, profesor, empresario o senador, nos evidenciaron que el meollo de la negociación -antes llamada conflicto- radica en acercar posiciones entre lo que puede dar la empresa sin quedar fuera la competencia y lo que exigen los trabajadores según sus aspiraciones, necesidades y riesgos de perder temporalmente sus ingresos por la huelga, o indefinidamente por la ruina de la empresa.

6. Nuestra experiencia personal, a través de muchas negociaciones efectuadas principalmente entre mediados de los años cuarenta y mediados de los sesenta -fecha en que debimos asumir responsabilidades ministeriales- fue bastante exitosa en aprovechar la credibilidad que la condición de asesor legal de sindicato nos proporcionaba ante los trabajadores, y la responsabilidad de ser profesional universitario, académico y comprometido con una solución que ojalá evitara la huelga, extendía de alguna manera esa credibilidad a la representación empresarial. Lo difícil era ganar una confianza, sin perder la otra, insertando en la función de asesor sindical muchos elementos propios del mediador y aun del árbitro. En realidad, empresarios y trabajadores buscaban evitar la, huelga pero subsistían los "fantasmas" de la lucha clasista y del imperio del lucro, que llevaba a los líderes extremistas a impulsar la huelga como herramienta de movilización social, o, por la otra punta, a procurar el arreglo más barato posible para el capital, y no el más equitativo, capaz de asegurar la paz y la justicia en la empresa, mirada como comunidad de esfuerzos entre trabajadores, ejecutivos e inversionistas para producir bienes o servicios útiles a la sociedad y convenientes para todos y cada uno de los sectores.

7. Los parámetros en aquellas décadas eran muy diferentes de los actuales, porque también diferían las circunstancias, las políticas y leyes en aplicación. Por ejemplo, en muchos casos la solución dependía de que el Gobierno fijara nuevos precios a ciertos productos, en forma que los consumidores pagaban el mayor costo de la solución. No faltaron las fundadas sospechas, en algún conflicto, de que él fuera originado en el interés de conseguir el alza de precios en los productos de la empresa, pretensión que más de una vez se pensó era compartida por ambos lados en la mesa de negociación. Tampoco existían, como hoy, los mecanismos de la mejor oferta de la empresa, o de la buelga concebida como una opción entre dicha oferta o la paralización de faenas. Se iba a la paralización en una pugna de presiones: nosotros no ganamos remuneraciones, pero ustedes no pueden producir. Ahora bien, si llegaba a perderse la votación de huelga por falta de quórum -no había votos en contra, salvo uno que otro testimonial, o despistado- los trabajadores perdían lo que tenían y lo que pedían. Había que partir del punto cero, porque el contrato colectivo anterior ya no existía y las negociaciones -o conflictos- se iniciaban al momento de expirar el contrato colectivo vi- 
gente, llamado generalmente acta de avenimiento. Si las negociaciones duraban, por ejemplo, cuarenta días, los nuevos beneficios regian desde la firma del nuevo contrato colectivo (o acta de avenimiento) y se discutían las condiciones en que se remuneraría el llamado retroactivo, o sea, el tiempo transcurrido entre la expiración del contrato anterior y la vigencia del nuevo contrato o acta de avenimiento. Fue en el Estatuto de los Trabajadores del Cobre de $1956^{2}$ y sus reformas posteriores donde nacieron los elementos de racionalidad, que ahora son moneda común (presentación del pliego de peticiones antes de la expiración del contrato colectivo anterior; la huelga como opción entre la mejor oferta o la pugna por superarla). Más tarde vendrían los beneficios con que se premia una oferta, que asegure reajuste de remuneraciones iguales o superiores al 100\% del aumento del IPC -Índice de Precios al Consumidor-; etcétera.

8. Hoy vivimos otro mundo. Lo que interesa es aproximarse a una solución partiendo de ciertas bases de datos que, ojalá, sean conocidas por ambas partes. En tal expectativa se funda la idea de elaborar algún software que tamice y otorgue mayor credibilidad a las posiciones de ambas partes. No pretendemos una fórmula científica que determine un nivel de solución preciso e incontrovertible en la negociación colectiva. En cambio, no parece un exceso imaginar que toda solicitud laboral u oferta empresarial resista un test de blancura, en el sentido que se encuadre dentro de un piso y un cielo tan cercanos que, mediante la negociación, no dejen margen útil para una solución vía huelga y fuercen a una transacción razonable, o un arbitraje con límites preestablecidos, los que pueden ser conocidos de todos, o bien solo del árbitro, según las circunstancias.

9. Algunos elementos que sin duda deberían tomarse en consideración para un avance en la dirección señalada, son:

a) Los que determinan el break even point, por parte de la empresa;

b) Los que permiten identificar cuáles son las empresas competidoras, según número y calidad de los trabajadores, sistemas productivos, ubicación en el mercado, antigüedad, capital y reservas, nivel de endeudamiento, clientela cautiva, ventas, posibilidades de desarrollo; riesgos o limitaciones políticas, comerciales, ecológicas, etc.;

c) Los que orientan sobre el precio de mercado de los productos de la empresa y los niveles de remuneraciones de trabajadores de similar calificación;

d) Los datos históricos de cómo han sido solucionadas negociaciones entre empresas y trabajadores de niveles comparables por épocas y circunstancias.

10. Es un dato del análisis la cautela con que deben evaluarse las experiencias de comienzos o mediados del siglo XX y, aun, otras posteriores, en una materia tan fluida $\mathrm{y}$ vertiginosamente cambiante. Por eso mismo se plantea con mayor urgencia el examen y esclarecimiento de la vigencia $\mathbf{u}$ obsolescencia de mecanismos mantenidos por las leyes o las prácticas de largas décadas, que operaron bajo otros cielos históricos. Con todo, vigentes u

\footnotetext{
2 BARRIGA UlLOA, Mario. Organización y funcionamiento del sindicato. Estatuto de los Trabajadores del Cobre. Osorno: Talleres Gráficos Cervantes, 1959.
} 
obsoletas desde el punto de vista técnico, el asunto reside precisamente en que legalmente o de facto se siguen aplicando y ha llegado el momento de someterlas a este verdadero test de permanencia o sustitución. Es el caso preciso de la huelga y su normativa. Ciertamente, no el único, pero sin duda emblemático. En los primeros pasos de este nuevo milenio, hay que trabajar sin descanso por reducir factores de irracionalidad o amoralidad que envuelve la fría y más que secular tensión que se manifiesta en el juego recíproco de pugna y aguante, bajo la amenaza de huelga o cierre de empresa, cuando parecen abundar elementos para una vía más ilustrada, justa y eficaz.

11. A comienzos de la década de 1990, junto con el desmembramiento y extinción de la URSS, se hirieron de muerte -nadie sabe por cuanto tiempo- las tácticas y hábitos del sindicalismo tradicional de lucha de clases, que había dejado, sin embargo, su huella en el derecho del trabajo defendido por la OIT, en especial, en el derecho colectivo del trabajo, que trata de los sindicatos; las negociaciones, conflictos y contratos colectivos; la huelga y el lockout o cierre de empresa. La Organización Internacional del Trabajo calzaba como una solución de inspiración social demócrata o social cristiana, con aceptación del liberalismo moderado. Era, en el fondo, una alternativa de ley y justicia, contra el marxismo leninista que buscaba agudizar las contradicciones del capitalismo, para hacer posible la revolución social. No olvidemos la frase de fuego con que coronaban en 1848 Marx y Engels su Manifiesto:

"Los comunistas repudian disimular sus ideas y propósitos. Declaran abiertamente que sus fines solo pueden lograrse por la subversión violenta de todo el orden social existente. Bien pueden temblar las clases dominantes ante una revolución comunista. Los proletarios nada tienen que perder en ella, salvo sus cadenas. Tienen un mundo por ganar. ¡Proletarios de todos los países, uníos!" 3.

Según cálculos provenientes de un prolijo estudio posterior a la caída de la URSS, podríamos decir que esta frase, de encendido ímpetu revolucionario, le costó al mundo alrededor de 100.000 .000 de muertos $^{4}$, la gran mayoría trabajadores y muchísimos de ellos marxistas.

12. Así, a Dios gracias, los violentos y abiertos conflictos colectivos de principios de siglo se han tornado obligadamente más racionales y reglados. Los obreros analfabetos devinieron, en creciente proporción, trabajadores calificados, cuya mayor cultura les enseñó que ninguna presión sindical podía otorgar lo que proporcionan la formación profesional y el entrenamiento ocupacional. Más todavía: mientras más alta es la calificación de un profesional, más recelo ha llegado a generar en él la negociación colectiva a la antigua, propensa a buscar soluciones de promedio, favorables a los trabajadores de más bajas remuneraciones y menor productividad, que se explicaban y justificaban en un escenario histórico inasimila-

\footnotetext{
${ }^{3}$ ENGELS, F. y MARX, C. Manifiesto Comunista. Santiago: Editorial Universitaria, 1970, pp. 69-70.

4 Courtols, Stéphane. "Los Crímenes del Comunismo". Introducción a Courtols, WerTh, PanNe, PaCzKOWSKI, BARTOSEK y MARGOLIN. El Libro Negro del Comunismo. Madrid: Editoriales Laffont, Espasa Calpe y Planeta, 1997/1998, p. 18.
} 
ble al de hoy. Por otro lado, la abundancia de la información y el perfeccionamiento de las ciencias económicas, la informática y la computación indujeron por causas técnicas y culturales a lo que por razones profesionales y de justicia buscábamos los abogados laboralistas a mediados del siglo XX: moderar los máximos que podía exigir la parte laboral, para no comprometer la estabilidad o capacidad ocupacional de la empresa, y pugnar por el mejoramiento de la oferta de la empresa, para que esta no distara de la anterior, ni quedara por debajo del mejor nivel soportable sin desestabilizar la empresa ni perjudicar el pleno empleo. Este complejo de relaciones, que difícilmente alcanzará una plena certeza, siempre dejará márgenes de discusión, pero tiende a estrechar el ámbito dentro del cual se justifican las pérdidas que para ambas partes genera una huelga o paralización, suponiendo que esta, una vez desatada, por lo común demorará 15 o más días en regularizar la situación -medio mes de producción y de remuneraciones-. De esta manera, la huelga que era "la expresión máxima de las clases asalariadas" 5 , podría estar cerca de transformarse en una especie de seguro contra abusos ostensibles, o formas de expresión de una protesta política, ajena por lo común al mundo propio de las relaciones entre sindicato y empresa. Las condiciones y opciones de este proceso son las que tratamos de identificar.

13. Hoy, que predomina en el mundo -con peculiaridades y variantes- la economía social de mercado como base de las relaciones económicas, se presentan tres opciones a las sociedades que procuran inspirarse en ella:

a) Una tendencia hacia la antigua derecha extrema, interesada en aprovechar la debilidad del sindicato para poner fin de una vez por todas al molesto adversario, enemigo jurado de la empresa privada;

b) Un extremismo nostálgico del marxismo, que no olvida la confrontación de clases como la herramienta más segura para dar nuevos bríos al sindicalismo, y;

c) Un humanismo democrático y constructivo, de amplísimo espectro, pero poca claridad. A veces laico, a veces cristiano, o judeocristiano, que defiende la vigencia simultánea de la empresa privada y el sindicato -o sea, la libertad de emprender y la libertad sindical- y cuya vinculación debe estar presidida por una ética de respeto a la dignidad de las personas y una normativa de justicia, amistad, veracidad y confiabilidad en sus relaciones. Ciertamente en él se inserta, el humanismo cristiano, inspirado en las encíclicas sociales. En cuanto a Chile, no aparece -a fines de la década 2010una figura que lo encarne con mayor fidelidad y carisma que el padre Alberto Hurtado, canonizado como san Alberto Hurtado el 23 de octubre de 2005.

14. No disimulamos nuestra preferencia por la opción c), que debe concretarse en una nueva cultura laboral -complemento necesario del nuevo panorama político y económico que se impone nacional e internacionalmente- y, dentro de ella, no puede desdeñarse el objetivo de introducir racionalidad y la moralidad en el mundo de las relaciones de trabajo, individuales y colectivas.

\footnotetext{
${ }^{5}$ Medina, Andrés. Las Centrales Sindicales del Siglo XX. Chillán: Impresora la Discusión, 1999, p.105.
} 
William Thayer Arteaga / Utilidad de la buelga. Aproximación a un estudio sobre sus expectativas y costos

15. Por eso, desde hace tiempo venimos llamando la atención a las consecuencias que puede tener una errada interpretación de los convenios 87 y 98 de la OIT, relativos a libertad sindical y negociación colectiva, que entraron a regir el 1 de febrero del año 2000 y nos obligaron a organizar con mayor autonomía de las partes, menor intervención del Estado y más protagonismo de las organizaciones sindicales nuestras relaciones laborales. Sin embargo, abre una perspectiva de incertidumbre y conflictividad el hecho de que algunos profesores y abogados sostengan -a nuestro juicio equivocadamente- que la vigencia de los citados instrumentos internacionales "han modificado ipso jure las disposiciones de la Constitución y de las leyes chilenas que los contradigan". Al respecto, resulta más dañina la pérdida de la certeza jurídica que una legislación inconveniente o errada y esto ocurre cuando interpretaciones emanadas de autoridades, entes o personas de peso en la opinión pública, sostienen que los tratados internacionales, según el alcance que le atribuyen al texto vigente del artículo 5 inciso 2 de la Constitución, modifican tácitamente toda normativa que se les oponga, incluso la de nivel constitucional ${ }^{6}$.

16. Un ejemplo patente de la gravedad virtual de este asunto lo ofreció el grave conflicto laboral de los trabajadores portuarios, ocurrido entre marzo y abril del año 2000, que puso en jaque a buena parte de la industria exportadora de frutas y el prestigio exportador de Chile, causando daños irreparables, que pudieron ser aún mucho mayores y generar un descalabro para toda la actividad exportadora nacional, si no se hubiera resuelto con relativa prontitud. Alguien habló en esos días de aplicar la Ley de Seguridad Interior del Estado a los huelguistas si el asunto no tenía rápido arreglo. El análisis de su desenlace efectivo no es materia de este estudio, pero debe hacerse notar que, si hubiere sido necesario aplicar la citada ley, el precepto correspondiente, el artículo $11^{7}$, estaría modificado o derogado según la interpretación, que rechazamos, de algunos abogados y profesores. La disposición referida es del tenor siguiente:

"Artículo 11: Toda interrupción o suspensión colectiva, paro o huelga de los servicios públicos o de utilidad pública, o en las actividades de la producción, del transporte o del comercio, producido sin sujeción a las leyes y que produzca alteraciones del orden público o perturbaciones en los servicios de utilidad pública o de funcionamiento legal obligatorio o daño a cualquiera de las industrias vitales, constituye delito y será castigado con presidio o relegación menores en sus grados mínimo a medio.

En la misma pena incurrirán los que induzcan, inciten o fomenten algunos de los actos ilícitos a que se refieren el inciso anterior...".

17. Se relacionan con el precepto transcrito, los artículos 384 y 385 del Código del Trabajo, que en su parte pertinente disponen:

\footnotetext{
${ }^{6}$ Vid. Nuestro estudio Hacia una nueva cultura laboral. Efectos y proyecciones de la ratificación por Chile de los Convenios 87 y 98 de la OIT. Santiago: Fontaine Editores, $1999,120 \mathrm{p}$.

7 Texto fijado por el D.S. 890, Ministerio del Interior, D.O. de 26 de agosto de 1975, aclarado y complementado por el D.S. 1388 de 22 de diciembre de igual ańo.
} 
“Artículo 384. No podrán declarar la huelga los trabajadores de aquellas empresas que:

a) Atiendan servicios de utilidad pública 0 ,

b) Cuya paralización por su naturaleza cause grave daño a la salud, al abastecimiento de la población, a la economía del país o a la seguridad nacional.

Para que se produzca el efecto a que se refiere la letra b), será necesario que la empresa de que se trate comprenda parte significativa de la actividad respectiva del país, o que su paralización implique la imposibilidad total de recibir un servicio para un sector de la población.

La calificación de encontrarse la empresa en alguna de las situaciones señaladas en este artículo, será efectuada dentro del mes de julio de cada año, por resolución conjunta de los Ministros del Trabajo y Previsión Social, Defensa Nacional y Economía Fomento y Reconstrucción".

18. Conviene anotar que las empresas que se hallan en la condición del último inciso del artículo 384 son, mencionadas específicamente, por una comisión de tres ministros de Estado, asunto de parecida naturaleza es la regla del artículo 385, que reglamenta el decreto de reanudación de faenas en caso de producirse huelga o lockout que por sus características, oportunidad o duración causare grave daño a la salud, al abastecimiento de bienes o servicios de la población, a la economía del país o a la seguridad nacional.

19. Este sistema de normas entra en conflicto con diversas resoluciones del Comité de Libertad Sindical de la OIT que, en algún momento nos traerá dificultades, que no es asunto de estas líneas examinar.

20. Creemos que con lo expuesto queda evidenciada la importancia de seguir con atención los criterios gubernamentales y técnicos respectivos en la interpretación de los citados Convenios que, particularmente, en relación con la huelga han generado una copiosa jurisprudencia que entre en conflicto con la normativa vigente y que no siempre nos parece susceptible de ser seguida. Por otro lado, nos parecen difíciles de controvertir los siguientes criterios, que por ahora solo dejamos esbozados, para profundizar en otra oportunidad.

21. En líneas generales, nuestra legislación procura insertar la huelga precisamente en el marco de la negociación colectiva, regulando sus efectos sobre la base de estimular la mejor oferta de la empresa, compatible con dos grandes objetivos sociales: dar empleo y asegurar buenas condiciones al mismo. En efecto, la clave de nuestro sistema es la opción de los trabajadores, manifestada en una amplia votación, entre la mejor oferta del empleador, por un lado, o la huelga para presionar por un mejoramiento de lo ofrecido, por otro. Ahora bien, el sistema alienta la negociación con un "piso", como hemos explicado, que supone mantención de todos los beneficios vigentes, reajustados en un $100 \%$ y seguridad de una similar reajustabilidad anual para el futuro. Si esta condición se cumple, los trabajadores negociarán solo mejoramientos reales, y no reajustes para compensar el alza del costo de la vida. Además, los huelguistas mantienen el derecho de efectuar trabajos remunerados fuera de la empresa, conservando su empleo en ella y pudiendo efectuar las imposiciones previsionales o de seguridad social -artículo 377-. Por su lado, el empleador que negocia con "piso" puede contratar desde el primer día de huelga reemplazantes provisionales, fuera del per- 
sonal en huelga. Respecto de este, el empleador que negocia "con piso", puede convenir el reintegro individual a contar del decimoquinto día, al menos en las condiciones de la mejor oferta comprometida -artículo 381, inciso 7-y le está prohibido ofrecerlo fuera de los casos específicamente autorizados -artículo 382-. Este panorama cambia y se endurece si no hay "piso", o sea, si la oferta empresarial no mantiene, en términos reales, todos los beneficios acruales. En este caso el empleador no puede contratar reemplazantes, sino a contar del decimoquinto día de huelga y el reintegro individual de los huelguistas solo se admite después del trigésimo día de huelga. No es la oportunidad de explicar en detalle aquí el régimen legal de huelga, del que depende, a su vez, el llamado lockout o cierre de empresa ${ }^{8}$, sino solo de evidenciar que es complejo y coherente; puede ser sustituido por otro, pero no privado de alguno de los elementos que le dan su coherencia, su lógica interna. Esta se enmarca en las exigencias de una economía social de mercado -altamente competitiva y difícil para un país en desarrollo y distante de los grandes centros comerciales- procurando armónicamente alto nivel de productividad, empleo y desarrollo y asignando a la huelga, en lo posible, el carácter de una instancia extrema de regulación del desacuerdo, mas no un carácter odioso de lucha de clases conflictivo. Por lo mismo, se presenta como una herramienta laboralmente eficaz a la par que temible y cara para la empresa, si no se ofrece una buena base de negociación. Por el contrario, se suaviza equilibradamente cuando la empresa acepta negociar con "piso". En todo caso, para la empresa moderna el uso de trabajadores reemplazantes constituye solo un remedio de emergencia, que atenúa, sin eliminar, los efectos más perniciosos de la huelga, pues jamás una empresa podrá enfrentar la competencia con un plantel de trabajadores provisionales y precarios, que deberán devolver sus cargos apenas los huelguistas decidan reintegrarse. La ley, además, ampara el accionar colectivo de los trabajadores, impidiendo reintegros individuales, por 15 días, si se negocia con "piso" y por 30 días, si la oferta empresarial no lo contiene.

22. Como se comprende, la aplicación al caso chileno de la jurisprudencia que no acepta la contratación de reemplazantes -criterio europeo, opuesto al norteamericano- destruiría el sistema, sin reemplazarlo por otro, salvo que se volviera al régimen de negociación conflictiva establecido en el Código de 1931, donde no se votaba por una opción entre la mejor oferta o la huelga, sino sencillamente por la huelga o contra ella. Esta nunca se rechazaba, pues en tal caso no había nada garantizado. Así los resultados del conflicto dependían de la fuerza y no de la razón; de la capacidad de los trabajadores para resistir sin remuneración, o de la empresa, para aguantar las pérdidas de no producir.

23. Respecto de las huelgas de protesta, de solidaridad y demás, no hay reglamentación en Chile, aunque son frecuentes en la administración pública, servicios públicos, profesorado, transportes, puertos, etcétera y, en cualquier sector, cuando aparece una clara justificación moral y social. Por ejemplo: incumplimiento flagrante de sus deberes por el empleador; u ofensa indignante y no excusada en contra de uno más trabajadores, o casos similares. Naturalmente no rigen obligatoriamente en situaciones similares, fueros, mejores

\footnotetext{
${ }^{8}$ Vid. Modificaciones hechas por la ley No 19.759 y nuestro Texto, comentario y jurisprudencia del Código del Trabajo. Santiago: Editorial Jurídica de Chile, 2010, pp. 505-536.
} 
ofertas, reserva de cargos, etcétera. Desde el punto de vista del Código del Trabajo, un paro injustificado constituye causal de caducidad de contrato, conforme al artículo 160. Ahora bien, la posibilidad de invocar tal caducidad dependerá de muchos factores y, en definitiva, de la base moral, la situación política o la fuerza correlativa de las partes en conflicto. Solo si se trata de paralizaciones en servicios públicos, de utilidad pública, o en actividades de la producción, el transporte o el comercio, producidos sin sujeción a las leyes y que produzcan alteraciones del orden público o perturbaciones en los servicios de utilidad pública o de funcionamiento legal obligatorio o dańo a cualquiera de las industrias vitales, se comete delito castigado, por la Ley de Seguridad Interior del Estado, con presidio o relegación menores en sus grados mínimo a medio. Igual pena se aplicará a quienes induzca, inciten o fomenten alguno de los actos ilícitos recién mencionados -artículo 11, ley 12.927, texto actualizado por decreto $\mathrm{N}^{\circ}$ 890, publicado en el Diario Oficial de 26 de agosto de 1975, aclarado y complementado por el decreto supremo $\mathrm{N}^{\circ} 1.388$, Diario Oficial de 10 de diciembre del mismo año-. Las responsabilidades civiles se rigen por el derecho común. La realidad suele ser que dichas sanciones, más que una espada de Damocles suspendida sobre la cabeza de los infractores, suele amenazar la de quienes pretenden aplicarlas, lo cual da origen a una confusa negociación en que nadie sale muy bien parado.

24. Dentro de los propósitos de avanzar hacia la elaboración de algún software que nos permita purificar de excesos o defectos las proposiciones de ambas partes en una negociación colectiva, acercar a un acuerdo y distanciar la huelga, señalamos a un grupo de alumnos de ingeniería civil en computación de una universidad de Santiago 9 algunos elementos a considerar para una mejor inteligencia de la evolución de los conflictos colectivos del trabajo, varios de los cuales hemos mencionado con anterioridad. Además, sugerimos otros, como parte de una hipótesis de trabajo que debería ser corregida' en la investigación. Los resumimos a continuación ${ }^{10}$ :

Entre inicios y fines del siglo XX, los conflictos colectivos laborales han evolucionado:

1. De violentos a pacíficos;

2. De abiertos a reglados;

3. De recíprocamente desinformados a recíprocamente informados;

4. De agrupar obreros analfabetos o de baja escolaridad, a operar, sin distingo entre empleados y obreros, con trabajadores con ocho o, más años como promedio de escolaridad;

5. De agrupar obreros de baja o nula calificación, a integrar trabajadores crecientemente calificados en número y nivel;

6. De personal fácilmente reemplazable, a personal de más difícil y costosa sustitución;

7. De una presión global por intereses comunes, a un colectivo laboral compuesto por grupos de trabajadores de similar calificación dentro de cada grupo, pero con diferente calificación cada grupo respecto de los otros. Incluso, debe anotarse un incremento

\footnotetext{
${ }^{9}$ Universidad Las Condes -hoy Universidad del Desarrollo-, 1998.

${ }^{10}$ Documentos de archivo Thayer, Universidad Finis Terrae.
} 
de las preferencias por la negociación individual en la medida en que la calificación es particularmente alta;

8. De fuerte expectativa en el éxito fundado en la presión sindical, a una progresiva convicción de que el nivel de remuneraciones depende sustancialmente de la calificación y no de dicha presión;

9. De nula conciencia acerca de los límites económicos de las aspiraciones laborales en cuanto no perturbar el pleno empleo, a una creciente preocupación por no ver comprometida la estabilidad en el trabajo por pérdida de competitividad de la empresa;

10. De un principal protagonismo del Estado dentro de la negociación -juntas de conciliación, mediadores-, o fuera de ella, pero vinculadas a la misma -fijación de precios o tarifados únicos-, a un mayor protagonismo de trabajadores y empresarios, con papel subsidiario del Estado;

11. De un manejo intuitivo o vulgar de los datos, a una progresiva fundamentación científica de las peticiones y ofertas;

12. De nula o limitada conciencia pública del deber moral, la necesidad política y la conveniencia económica de mantener buenas relaciones humanas y laborales dentro de la empresa, la profesión, el sector, el país y la comunidad internacional, a una creciente atención hacia esos temas;

13. De un sindicalismo de lucha de clases -lo que tú ganas, lo pierdo yo- a uno más participativo -si tú no ganas, no gano yo-, y

14. De un sindicato seguro, compenetrado de su función de lucha, a otro que aún no asimila las ventajas de la participación, y se considera debilitado por la pérdida del espíritu de lucha de clases, que aún no se internaliza como un sentido de "lucha por la justicia social", según la enseñanza de Juan Pablo II ${ }^{11}$.

Por otra parte, es indisimulable el efecto producido en el sindicalismo dominado por la influencia marxista, el desmembramiento de la URSS; la caída de los llamados socialismos reales, de economía planificada y centralizada, respaldados por una política fuertemente restrictiva de las libertades y los derechos humanos. Precisamente el grupo de alumnos de Ingeniería civil en Computación de la entonces Universidad Las. Condes -hoy U. del Desarrollo- a quienes tuvimos oportunidad de sugerirles una indagación en el asunto, avanzó en tal sentido y, bajo la dirección del profesor Germán Campos, entregó el 15 de enero de 1999 sus conclusiones tentativas al respecto, que nos parece pertinente comentar ${ }^{12}$.

25. El estudio se inicia precisando su objetivo, que consiste en la búsqueda de criterios para prevenir y evitar una huelga, aprovechando elementos que pudiera proporcionar un software adecuadamente concebido y alimentado para ese fin. Los condicionantes principales que el se procuró despejar y examinar fueron:

\footnotetext{
${ }^{11}$ Laborem Exercens, $\mathrm{N}^{\circ} 20$.

${ }^{12}$ Aldo Valenzuela, Silvio Brondi, Carlos Ramirez, Jorge Chahuán, Felipe Villarroel, David Campopdonico, Humberto de CAMPOS, Lourdes BARBEITO, Mauricio DONOSO y Enrique SOTO. Análisis de los criterios para prevenir y evitar el conflicto laboral. Santiago: Universidad de Las Condes -actual Universidad del Desarrollo-, 1999, 115p.
} 
a) Metodología y experiencias para clasificar las empresas, procurando aproximarse a criterios que permitan identificar las involucradas en la competencia que afecte al progreso y desenlace de una negociación colectiva;

b) Clasificación de los trabajadores, con similares propósitos;

c) Elementos para evaluar la estabilidad de las empresas; $y$

d) Formas de determinar el break even point.

El estudio no puede ser resumido aquí, pero reflejó:

1. La pertinencia del mismo;

2. La falta de experiencias valederas, por tratarse de un esfuerzo por ahora solo tentativo e inductivo a ser profundizado en su riqueza y complejidad, y

3. Dificultades de parte de los organismos concernidos para proporcionar los antecedentes requeridos, temor a incurrir en responsabilidades en cuanto a proporcionar información que pudiera estimarse reservada.

Con todo, juzgamos que el trabajo abre un camino que requiere ser mejor habilitado y más recorrido.

26. Dos estudios del profesor Alberto J. Armstrong, de la Escuela de Administración de la Pontificia Universidad Católica ${ }^{13}$ son especialmente ilustrativos de la situación de la huelga en la actualidad, con datos internacionales, pero concretas apreciaciones sobre Chile.

Ambos trabajos están muy relacionados y el segundo aprovecha y sistematiza en gran medida la información del primero. De este, deseamos citar textualmente algunos comentarios que consideramos relevantes y oportunos:

“...una de las principales razones por las cuales los países han diseñado y establecido procesos de negociación colectiva ha sido asegurarse, hasta donde sea posible, que ambas partes hayan hecho un esfuerzo serio para llegar a un acuerdo antes de hacer uso de la huelga o del lockout, dados los costos o los efectos que generalmente tienen sobre la comunidad o sobre terceras partes que no están involucradas de manera alguna en la situación"14.

"En la inmensa mayoría de los casos, la posición inicial de arreglo contempla puntos o peticiones que los trabajadores no esperan realmente lograr, por cuanto responden a una estrategia de negociación que en Chile se ha denominado "política del tejo pasado"... La principal explicación de este proceder se encuentra en una de las características del proceso de negociación colectiva consistente en que ambas partes desconocen mutuamente el punto -denominado "posición final de arreglo"- hasta el cual la otra está dispuesta a ceder, o el máximo que está dispuesta a ofrecer para evitar

\footnotetext{
13 1. Tendencias, magnitud y causas de las buelgas de trabajadores dependientes de un empleador en Chile. Separata de Estudios de Administración vol. 4, No 1, 1997,78p. 2.- Marco General de Referencia sobre Negociación Colectiva y Huelgas. Documentos de Trabajo, 1999, 44p

14 Ibid.
} 
el costo de la huelga. Por mucho que el sindicato -o la empresa en su caso- realice todos los cálculos necesarios para determinar la posición final de arreglo de la empresa, será muy difícil que esté cien por ciento seguro de ella y, por lo tanto, lo que más se puede hacer es establecer el rango dentro del cual podría encontrarse dicha posición final de arreglo e iniciar negociaciones, demandando al menos lo calculado como el límite superior del rango. Proceder de esta manera implicaría utilizar racionalmente "la política del tejo pasado", ya que para la empresa el costo de lo solicitado estaría relativamente cercano al costo de su propia posición final de arreglo..."15.

No puede estar mejor expresada que en las palabras del profesor Armstrong, la que podríamos considerar premisa mayor, del silogismo en que pretendemos fundarnos:

- Mayor: El desconocimiento recíproco de la posición final de arreglo dificulta las negociaciones y acerca a la huelga o el lockout;

- Menor: Es así que el avance de la información disminuye el desconocimiento recíproco y habilita para saber anticipadamente al menos el rango en que sẹ mueven las pretensiones de ambas partes;

- Conclusión: Luego, el avance de la información aleja la huelga.

27. Pero hay más. El progreso de la información no solo confiere mayor transparencia a las posiciones de ambas partes, sino que la ciencia económica tiende a fijarles el rango progresivamente más estrecho, porque traspasarlo comprometería la estabilidad del empleo al dejar fuera de competencia a la empresa. Esto implica la concurrencia de dos factores. Por un lado, la empresa va a preferir cualquier duración de la huelga, antes que ser forzada a quedar fuera de la competencia, que equivale a su ruina y cierre. Por otro, los trabajadores van a perder en la huelga larga mucho más que el rango posible de sus expectativas de ganancia mediante ella y, además, para muchos de ellos -reducción de persona- o para todos -cierre de la empresa-, la pérdida del empleo y con él del soporte de todo mejoramiento económico.

El nuevo silogismo podría enunciarse así:

- Mayor: Para un contrato colectivo de dos años, la huelga de un mes de duración implica aproximadamente la pérdida de un $4.16 \%$ de las remuneraciones de todo èl período.

- Menor: Es así que si las exigencias del colectivo laboral son iguales o menores que un mejoramiento real del $4.16 \%$ de las remuneraciones y conducirán a una huelga de más de un mes, porque la empresa no está en condiciones económicas de aceptarlas, absorber ese mayor costo sin quedar fuera de la competencia o trabajar a pérdida,

- Conclusión: Luego, la huelga deja de ser un instrumento útil a los trabajadores si los hace pagar un precio mayor que la ganancia del improbable mejoramiento buscado.

${ }^{15}$ Ibid. 
Creemos que el juego complementario y decantado de: a) las modernas relaciones laborales, que mejoran la comunicación entre las partes; b) la ciencia económica, que precisa los rangos de las diferencias; c) una nueva cultura laboral, fundada en el "es preciso que tú ganes, para que yo gane" (de la economía social de mercado), y no en "lo que tú ganas me lo quitas a mí" (de la plusvalía marxista), debe provocar, como ya se advierte, un progresivo acercamiento a la obsolescencia de la huelga. Con razón era considerada a comienzos y mediados del siglo XX como la herramienta eficaz de mejoramiento social para los trabajadores. Con la misma razón hoy debe mantenerse, como un seguro para casos extremos de ceguera o injusticia, similares a los de una legítima defensa en derecho penal. 